\title{
PENGARUH KESELAMATAN DAN KESEHATAN KERJA TERHADAP KINERJA KARYAWAN PADA PABRIK KARET PT. KIRANA SAPTA DI PANOMPUAN
}

\author{
Abdul Nasser Hasibuan, Ja'far Nasution, Wiwik Susanti Sitompul \\ IAIN Padangsidimpuan \\ Jalan T. Rizal Nurdin Km. 4,5 Sihitang, Padangsidimpuan \\ Email:
}

\begin{abstract}
Abstrak,
Permasalahan dalam penelitian ini berkaitan dengan keselamatan dan kesehatan kerja. Untuk itu perlunya manajemen yang baik. Perusahaan memperhatikan kondisi kerja yang lebih aman dan lebih sehat. Serta menjadi lebih bertanggung jawab atas kegiatan - kegiatan tersebut, terutama bagi organisasi organisasi yang mempunyai tingkat kecelakaan yang tinggi. Penelitian ini bertujuan untuk mengetahui apakah pengaruh keselamatan dan kesehatan kerja secara parsial dan simultan berpengaruh terhadap kinerja kayawan. Untuk mengetahui apakah pengaruh keselamatan dan kesehatan kerja berpengaruh signifikan terhadap kinerja karyawan. Populasi pada penelitian ini adalah 400 karyawan dan sampel yang diambil untuk penelitian ini adalah 63 responden dengan menggunakan formula Slovin dengan taraf signifikasi $10 \%$ atau $(0,1)$. Teknik pengumpulan data yang digunakan dalam penelitian ini adalah metode angket/kuesioner, metode dokumentasi, dan metode wawancara. Analisa data yang digunakan dalam penelitian ini menggunakan analisa regresi berganda dengan taraf sig $<0,1$. Hasil analisa regresi ganda diperoleh koefisen regresi $\left(\mathrm{R}^{2}\right)$ sebesar $0,156(\mathrm{~F}=3,15$; $\operatorname{sig} 0$, ooo< 0,1). Hal ini menunjukkan bahwa pengaruh keselamatan dan kesehatan kerja mempunyai pengaruh terhadap kinerja karyawan secara bersama-sama. Serta masing- masing variabel independent perpengaruh positif terhadap variabel dependent kinerja karyawan yakni secara reliabel o, 672 dan o, 676 dengan tingkat signifikasi $<0,1$. Melalui analisa regresi berganda $\mathrm{Y}=43,102+0,583+0,825$. Hasil penelitian ini menunjukkan bahwa pengaruh keselamatan dan kesehatan kerja memiliki pengaruh yang signifikan secara parsial dan simultan teehadap kinerja karyawan.
\end{abstract}

Kata Kunci: Keselamatan, Kesehatan dan Kinerja Karyawan

\section{Abstract,}

The problems in this study relate to occupational safety and health. For this reason, the need for good management. Companies pay attention to safer and healthier working conditions. As well as being more responsible for these activities, especially for organizations that have high accident rates. This study aims to determine whether the influence of occupational safety and health partially and simultaneously influences employee performance. To find out whether the influence of occupational safety and health has a significant effect on employee performance. The population in this study were 400 employees and the samples taken for this study were 63 respondents using the Slovin formula with a significance level of $10 \%$ or (o.1). Data collection techniques used in this study were questionnaire / questionnaire method, documentation method, and interview method. Analysis of the data used in this study used multiple regression analysis with a level of sig $<0,1$. The results of multiple 


\section{PENGARUH KESELAMATAN DAN KESEHATAN KERJA TERHADAP KINERJA KARYAWAN PADA PABRIK KARET \\ PT. KIRANA SAPTA DI PANOMPUAN}

regression analysis obtained regression coefficients $(\mathrm{R} 2)$ of $\mathrm{o}, 156(\mathrm{~F}=3.15$; sig $\mathrm{O}$, ooo <0.1). This shows that the influence of occupational safety and health has an influence on employee performance together. And each of the independent variables positive influence on the dependent variable of employee performance is reliably $\mathrm{o}$, 672 and 0,676 with a significance level of $<0.1$. Through multiple regression analysis $\mathrm{Y}=43,102+0,583+0,825$. The results of this study indicate that the effect of occupational safety and health has a significant influence partially and simultaneously on employee performance.

\section{PENDAHULUAN}

PT. KIRANA SAPTA di Panompuan merupakan perusahaan swasta yang bergerak pada bidang industri karet. Pengolahan dan perindustriannya mengolah bahan baku menjadi bahan setengah jadi. Perusahaan ini terletak di Jl. Raya Aek Godang Gunung Tua km. 26, Angkola Timur, Tapanuli Selatan. Industrialisasi ini tidak terlepas dari sumber daya manusia, yang dimana setiap manusia diharapkan dapat menjadi sumber daya siap pakai dan mampu membantu tercapainya tujuan perusahaan dalam bidang yang dibutuhkan. Oleh karena itu dibutuhkan suatu kinerja yang baik untuk keberlangsungan perusahaan.Seperti yang kita ketahui kinerja yang baik harus menghasilkan kuantitas yang meningkat. Dapat kita ketahui dari tabel hasil kinerja tahun $\mathbf{2 0 1 0}$ - $\mathbf{2 0 1 5}$ adalah sebagai berikut :

Tabel 1.1

Hasil Kinerja Dari 2010-2015

\begin{tabular}{|c|c|}
\hline Tahun & $\begin{array}{c}\text { Hasil } \\
\text { kinerja/Tahun }\end{array}$ \\
\hline 2010 & 1000 Ton \\
\hline 2011 & 900 Ton \\
\hline 2012 & 100 Ton \\
\hline 2013 & 900 Ton \\
\hline 2014 & 1000 Ton \\
\hline 2015 & 700 Ton \\
\hline
\end{tabular}

Dari tabel tersebut menunjukkan terjadinya fluktuasi yang menjelaskan bahwa faktor sumber daya manusia memegang peranan yang paling penting dan utama dalam proses produksi, karena alat produksi tidak akan berjalan tanpa dukungan dan keberadaan sumber daya manusia.

Keberlangsungan sebuah perusahaan dalam meningkatkan kinerja karyawan diperlukan adanya manajemen yang baik, khususnya yang berkaitan dengan keselamatan dan kesehatan kerja (K3). Untuk itu, penerapan peraturan perundang - undangan dan pengawasan serta perlindungan para buruh sangat menentukan sistem manajemen industri yang baik dengan menerapkan $\mathrm{K}_{3}$ secara optimal. Berikut ini adalah data jumlah karyawan dan data kecelakaan kerja pada bagian pengolahan karet PT. KIRANA SAPTA di Panompuan yaitu : 
Tabel 2.1

Data karyawan bagian pengolahan karet PT. KIRANA SAPTA di Panompuan Tahun 2025 - 2017

\begin{tabular}{|r|l|c|}
\hline No & \multicolumn{1}{|c|}{ Jabatan } & $\begin{array}{c}\text { Jumlah } \\
\text { karyawan }\end{array}$ \\
\hline 1. & Mandor & 15 \\
\hline 2. & $\begin{array}{l}\text { Operator Press Packing/Karyawan shif } \\
\text { pagi ( 08. oo - 16. oo WIB) }\end{array}$ & 50 \\
\hline 3. & $\begin{array}{l}\text { Operator Press Packing/Karyawan shif } \\
\text { siang (15. 00 - 01. 00 WIB) }\end{array}$ & 50 \\
\hline 4. & $\begin{array}{l}\text { Operator Press Paking/Karyawan shif } \\
\text { malam (22. oo - 09. oo WIB) }\end{array}$ & 50 \\
\hline
\end{tabular}

Sumber : PT. KIRANA SAPTA di Panompuan 2017 - 2018

Tabel 3.1

Data kecelakaan kerja pada bagian pengolahan karet PT. KIRANA SAPTA di Panompuan

\begin{tabular}{|c|c|l|}
\hline Tahun & Jumlah & \multicolumn{1}{|c|}{ Keterangan } \\
\hline 2015 & 4 & $\begin{array}{l}\text { 55\% akibat tidak memakai } \\
\text { pelindung/perlengkapan, 30\% } \\
\text { akibat kelalaian/kurang berhati } \\
\text { - hati, 25\% akibat kurangnya } \\
\text { pengawasan }\end{array}$ \\
\hline 2016 & 7 & $\begin{array}{l}\text { 75\% tidak memenuhi aturan } \\
\text { kerja, 25\% tidak menggunakan } \\
\text { pelindung }\end{array}$ \\
\hline 2017 & 3 & $\begin{array}{l}\text { 69\% tidak memenuhi aturan } \\
\text { kerja, 31\%tidak menggunakan } \\
\text { pelindung. }\end{array}$ \\
\hline
\end{tabular}

Sumber : PT. KIRANA SAPTA di Panopuan 2015 - 2017

Berdasarkan tabel di atas dapat dijelaskan bahwa jumlah kecelakaan yang terjadi pada tahun 2015 sebanyak 4 kali, sedangkan tahun 2016 sebanyak 7 kali, dan pada terakhir yaitu tahun 2017 sebanyak 3 kali. Kecelakaan kerja berhubungan dengan kinerja di perusahaan. Jenis kecelakaan yang terjadi antara lain yaitu : terhirup atau terjadinya kontak antara kulit dengan hidrokarbon dan abu, gas, uap steam, asam dan embun yang beracun, terkena benturan keras, terpotong saat memotong karet, jatuh terpeleset. Berdasarkan pengamatan penelitian serta hasil wawancara dengan bapak Hermansyah Tanjung selaku koordinator PT. KIRANA SAPTA di Panompuan masih ada karyawan yang tidak mematuhi prosedur $\mathrm{K}_{3}$ atau 


\section{PENGARUH KESELAMATAN DAN KESEHATAN KERJA TERHADAP KINERJA KARYAWAN PADA PABRIK KARET PT. KIRANA SAPTA DI PANOMPUAN}

kesalahan dalam peralatan yang digunakan oleh karyawan pada waktu melaksanakan pekerjaan. Perusahaan harus memberikan sanksi yang tegas dimana kurangnya kesadaran karyawan atau tidak memakai perlengkapan keselamatan kerja sesuai dengan prosedur yang sudah ditetapkan. Hal tersebut akan berdampak kepada perusahaan yaitu kurang atau tidak efesiennya pencapaian tujuan pekerjaan bahkan juga kepada karyawan dimana menurunnya kinerja karyawan akibat kecelakaan kerja serta kondisi kesehatan yang kurang baik.

Berdasarkan uraian latar belakang di atas, maka peneliti merasa tertarik mengungkap masalah tersebut dengan melakukan penelitian dengan judul: "Pengaruh Keselamatan dan Kesehatan Kerja Terhadap Kinerja Karyawan Pada Pabrik Karet PT. KIRANA SAPTA di Panompuan”.

\section{TINJAUAN TEORITIK}

\section{Kinerja Karyawan}

Istilah kinerja berasal dari kata Job performance atau actual performance. Pengertian kinerja adalah hasil kerja secara kualitas dan kuantitas yang dicapai oleh seorang karyawan dalam melaksanakan tugasnya sesuai dengan tanggung jawab yang diberikan kepadanya (A. A Anwar Prabu Mangkunegara, 2012). Kinerja merupakan sistem formal yang digunakan untuk mengevaluasi kinerja pegawai secara priodik yang ditentukan oleh organisasi (Surya Darma, 2005). Kinerja merupakan hasil pekerjaan yang mempunyai hubungan kuat dengan tujuan strategi organisasi, kepuasan konsumen dan memberikan kontribusi ekonomi. Pendapat dari para ahli lain, bahwa kinerja adalah gambaran mengenai tingkat pencapaian pelaksanaan atau kegiatan/program/kebijaksanaan dalam mewujudkan sasaran, tujuan, misi, dan visi organisasi yang tertuang dalam perumusan skema strategi (strategic planning) suatu organisasi (Akdon, 2011).

Dalam persfektif Islam bekerja tidak hanya sebagai ibadah saja, karena pekerjaan merupakan yang frekuensi logisnya adalah amal (balasan) yang kita terima. Dalam konteks ini pekerjaan tidak hanya bersifat ibadah dan ukhrowi, akan tetapi juga kerja-kerja sosial yang bersifat duniawi.Adapun firman Allah SWT dalam surah At- Taubah ayat 105 antara lain :

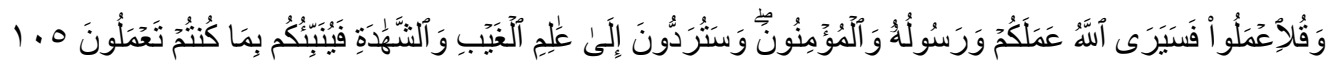

Artinya:bekerjalah kamu, maka Allah dan Rasul-Nya serta orang-orang mukmin akan melihat pekerjaanmu itu, dan kamu akan dikembalikan kepada (Allah) yang mengetahui akan yang ghaib dan yang nyata, lalu diberitakan-Nya kepada kamu apa yang telah kamu kerjakan. 
Bekerjalah kamu karena Allah, semata dengan aneka amal yang saleh dan bermanfaat, baik untuk diri kamu maupun untuk masyarakat umum, maka Allah akan melihat, yakni menilai dan memberi ganjaran amal kamu itu, dan rasul-Nya serta orangorang mukmin akan melihat amal-amal kamu itu dan kamu akan dikembalikan melalui kematian kepada Allah swt. Yang Maha mengetahui yang ghaib dan yang nyata, lalu diberitakan-Nya kepada kamu sanksi dan ganjaran atas apa yang telah kamu kerjakan, baik yang tampak ke permukaan maupun yang kamu sembunyikan dalam hati.

\section{Keselamatan dan Kesehatan Kerja}

Pengertian keselamatan kerja adalah perlindungan para pekerja dari luka-luka yang diakibatkan oleh kecelakaan yang berkaitan dengan pekerjaan (Marwansyah, 2014). Keselamatan kerja merupakan hal yang penting bagi perusahaan karena dampak suatu kecelakaan tidak hanya merugikan karyawan, tetapi juga perusahaan secara langsung maupun tidak langsung (Rika Hampuh Hadiguna, 2009). Keselamatan kerja adalah menunjukkan kondisi yang aman atau selamat dari penderitaan, kerusakan atau kerugian di tempat kerja. Resiko keselamatan merupakan aspek - aspek dari lingkungan kerja yang dapat menyebabkan keseleo, patah tulang, terpeleset, luka memar, kehilangan alat tubuh, penglihatan dan pendengaran.Semua itu sering dihubungkan dengan perlengkapan perusahaan atau lingkungan fisik yang mencakup tugas-tugas yang membutuhkan pemeliharaan dan pelatihan.

Manajemen sebagai salah satu ilmu yang mencakup aspek sosial yang sangat bermanfaat dalam pengolahan keselamatan dan kesehatan kerja, baik dari segi perencanaan maupun pengambilan keputusan dalam organisasi. Untuk mengurangi tindakan dan kondisi kerja yang tidak aman, maka pihak manager pabrik harus memiliki komitmen yang kuat dalam menegakkan kedisiplinan kerja kepada penghargaan, pengorganisasian untuk memonitoring program keselamatan kerja, mekanisme koordinasi yang jelas, terukur dan audit secara periodik ke setiap bagian. Dengan demikian, asas yang digunakan dalam manajemen keselamatan kerja harus mencakup perencanaan maupun keputusan keputusan manajerial dan organisasi yang terintegrasi di setiap aspek operasional dan startegis perusahaan.Apabila kecelakaan kerja terjadi, maka seluruh pemangku kepentingan di dalam perusahaan yang harus ikut bertanggung jawab.

Sebagai seorang muslim sangat dianjurkan untuk bekerja. Dan bekerja mestilah dilakukan dengan niat semata-mata karena Allah untuk mendapat kebahagian hidup berupa rezeki di dunia, disamping itu tidak melupakan kehidupan di akhirat.Karena itu dalam Islam 


\section{PENGARUH KESELAMATAN DAN KESEHATAN KERJA TERHADAP KINERJA KARYAWAN PADA PABRIK KARET \\ PT. KIRANA SAPTA DI PANOMPUAN}

hendaklah menjadikan kerja sebagai ibadah bagi keberkatan rezeki diperolehnya. Sebagaimana dijelaskan firman Allah SWT dalam QS.Ar - Ra'd 11 sebagai berikut :

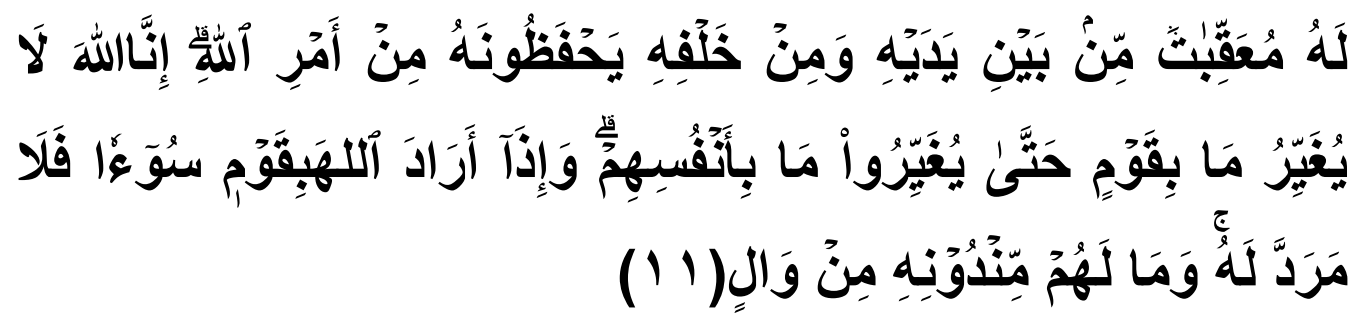

Artinya: Bagi manusia ada malaikat-malaikat yang selalumengikutinya bergiliran di muka bumi belakangnya, merekamenjaganyaatas perintahAllah. Sesungguhnya Allah tidak mengubah keadaan sesuatu kaum sehinggah mereka mengubah keadaan yang ada pada diri mereka sendiri.Dan apabila Allah menghendaki keburukan terhadap sesuatu kaum, maka tak ada yang dapat menolaknya; dan sekali - kali tak ada pelindung bagi mereka selain Dia. (Departemen Agama RI, 2010)

Berdasarkan ayat di atas dijelaskan bahwa Allah tidak akan merubah keadaan mereka sendiri, hal ini berarti jika ingin maju dan sukses maka manusia harus mau bekerja untuk mencukupi kebutuhan hidupnya. Allah tidak akan memberikan rezeki secara cuma cuma, Allah tidak akan memberi kesuksesan tanpa usaha. Kemudian pada kalimat selanjutnya disebutkan bahwa manusia tidak memiliki pelindung terhadap keburukan yang dikehendaki Allah, artinya bahwa manusia tidak bisa menghindar dari keburukan yang telah ditakdirkan oleh Allah untuk terjadi dalam hidup manusia. Tapi manusia berhak untuk menjaga keselamatan dan kesehatan dirinya dari ancaman yang terjadi dalam pekerjaanya, manusia harus tetap berusaha untuk menyelamatkan diri dari berbagai bahaya yang mengintai di lingkungan sekitarnya. Masalah selamat atau tidak, hal itulah yang kemudian menjadi kuasa Allah untuk menentukan garis hidup manusia. Jadi, manusia harus mau berusaha untuk merubah keadaanya.

Kesehatan kerja adalah bagian dari ilmu kesehatan yang bertujuan agar tenaga kerja memperoleh keadaan kesehatan yang sempurna baik fisik, mental maupun sosial sehingga memungkinkan dapat bekerja secara optimal (Lalu Husni, 2015). Menurut Undang Undang Republik Indonesia Nomor 23 Tahun 1992 tentang kesehatan, kesehatan adalah suatu keadaan sejahterah dari badan, jiwa, dan sosial yang memungkinkan setiap orang hidup produktif secara sosial dan ekonomis. Sementara kesehatan kerja dapat diartikan sebagai terbebasnya para pekerja dari penyakit fisik dan mental. Kesehatan kerja 
diselenggarakan untuk mewujudkan produktivitas kerja yang optimal. Kesehatan kerja meliputi pelayanan kesehatan kerja, pencegahan penyakit akibat kerja, dan syarat kesehatan kerja. Ketentuan yang sama juga menegaskan bahwa setiap tempat kerja wajib menyelenggarakan kesehatan kerja.

Kesehatan karyawan adalah menunjukkan pada kondisi yang bebas dari gangguan fisik, mental, emosi atau rasa sakit yang diseabkan oleh lingkungan kerja. Resiko kesehatan merupakan faktor - faktor dalam lingkungan kerja yang bekerja melebihi periode waktu yang ditentukan, lingkungan yang dapat membuat stress emosi dan gangguan fisik (A. A Anwar Prabu Mangkunegara, 2012). Jadi dapat disimpulkan kesehatan kerja bermaksud melindungi atau menjaga pekerja dari kejadian atau keadaan hubungan kerja yang merugikan kesehatan dalam melakukan suatu pekerjaan.Adanya penekanan dalam suatu hubungan kerja menunjukkan bahwa semua tenaga kerja yang tidak melakukan hubungan kerja dengan pengusaha tidak melakukan hubungan kerja dengan pengusaha tidak mendapatkan perlindungan sosial (Zaeni Asyhadie, 2008). Allah berfirman dalam QS.Alan'am : 17 yang berbunyi :

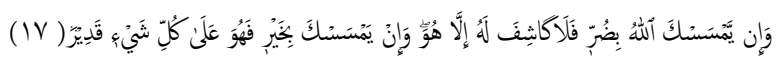

Artinya: Jika Allah menimpahkan sesuatu kemudharatan kepadamu, maka tidak ada yang menghilangkannya melainkan Dia sendiri dan Jika Dia mendatangkan kebaikan kepadamu, Maka Dia Maha Kuasa tiap tiap sesuatu.

Ayat di atas dapat disimpulkan bahwa islam adalah agama sangat menjungjung tinggi keselamatan bagi pemeluknya. Islam dalam Al qur'an dan Hadist melarang umat untuk membuat kerusakan jangankan kerusakan itu terjadi pada lingkungan, terhadap diri sendiri aja Allah malarangnya. Hubungannya $\mathrm{K}_{3}$ dengan islam adalah sama- sama meningkatkan umat manusia agar senantiasa berperilaku (berpikir dan bertindak) yang aman dan sehat dalam bekerja di tempat kerja (di kantor, pabrik, di tambang, dan sebagainya). Dengan berperilaku aman dan sehat akan tercipta suatu kondisi atau lingkungan yang aman dan sehat. Dengan bekerja yang aman di tempat kerja, akan membawa keuntungan bagi diri sendiri maupun perusahaan tempat kerja. Perusahaan sehat pekerja pun akan tenang dalam bekerja.

\section{Hubungan antara keselamatan dan kesehatan kerja karyawan dengan kinerja.}

Kinerja marupakan sesuatu aspek yang penting bagi perusahaan karena apabila tenaga kerja dalam perusahaan mempunyai kinerja yang tinggi maka perusahaan akan 


\section{PENGARUH KESELAMATAN DAN KESEHATAN KERJA TERHADAP KINERJA KARYAWAN PADA PABRIK KARET PT. KIRANA SAPTA DI PANOMPUAN} memperoleh keuntungan serta pencapaian tujuan perusahaan dapat terwujud. Untuk meningkatkan kinerja karyawan adanya tenaga kerja yang memiliki keterampilan dan keahlian bekerja, jika tidak akan berakibat menurunnya produktivitas atau kinerja karyawan dan dapat merugikan perusahaan. Kinerja dipengaruhi beberapa faktor lainnya seperti pendidikan , pelatihan, keahlian, kepemimpinan, dan lingkungan kerjayang mendukung.

Jika tidak diterapkan manajemen keselamatan dan kesehatan kerja maka masalah dibidang ini menimbulkan kerugian yang diakibatkan kecelakaan dan lingkungan kerja yang kurang sehat dan aman.Dalam lingkungan kerja seperti ini para karyawan merasa tidak enak dan tidak aman dalam bekerja, sehingga produktivitas dan efesiensi kerja dapat menurun. Keselamatan dan kesehatan kerja merupakan salah satu persyaratan untuk meningkatkan produktivitas atau kinerja karyawan. Maka dari itu $\mathrm{K}_{3}$ mutlak untuk dilaksanakan pada setiap jenis bidang pekerjaan tanpa kecuali. Upaya $\mathrm{K}_{3}$ diharapkan dapat mencegah dan mengurangi resiko terjadinya kecelakaan mapun penyakit akibat melakukan pekerjaan.

\section{Hipotesis}

Menurut (Noor, 2015), hipotesis merupakan jawaban sementara atau masih bersifat dugaan terhadap pertanyaan yang diajukan sebelumnya dan merupakan kesimpulan dari kerangka berpikir. Hipotesis yang baik harus sesuai dengan tema yang diteliti, harus konsisten dengan logika, dinyatakan secara ringkas dan dapat diuji. Berdasarkan rumusan masalah, maka hipotesis penelitian ini adalah :

$\mathrm{H}_{1} \quad=$ "Ada pengaruh keselamatan kerja terhadap kinerja karyawan pada pabrik karet PT. KIRANA SAPTA di Panompuan"

$\mathrm{H}_{2} \quad$ = "Ada pengaruh kesehatan kerja terhadap kinerja karyawan pada pabrik karet PT. KIRANA SAPTA di Panompuan”.

$\mathrm{H}_{3} \quad$ = "Ada pengaruh keselamatan dan kesehatan kerja secara simultan terhadap kinerja karyawan pada pabrik karet PT. KIRANA SAPTA di Panompuan”.

\section{METODE PENELITIAN}

Analisis data yang digunakan dalam penelitian ini agar sesuai dengan tujuan penelitian, guna mengetahui pengaruh keselamatan dan kesehatan kerja terhadap karyawan pada pabrik karet PT. Kirana Sapta di Panompuan yaitu dengan menggunakan rumus regresi linier berganda. Menurut (Gulo : 2010), jika variabel independen yang berhubungan dengan satu variabel dependen, maka analisis regresi tersebut disebut regresi linier berganda. Persamaan regresi linier berganda yang digunakan dalam penelitian ini adalah :

$$
\mathrm{Y}=\mathrm{a}+\mathrm{b}_{1} \mathrm{X}_{1}+\mathrm{b}_{2} \mathrm{X}_{2}+\mathrm{e}
$$

\section{Keterangan :}


$\mathrm{Y} \quad=$ Kinerja karyawan

$\mathrm{a} \quad=$ konstanta

b1 = koefisien untuk variabel keselamatan kerja

$\mathrm{b}_{2}=$ koefisien untuk variabel kesehatan kerja

$\mathrm{e}=$ eror

$\mathrm{X}_{1}=$ Keselamatan kerja

$\mathrm{X}_{2}=$ Kesehatan kerja

\section{Pengujian Asumsi Klasik}

Uji asumsi klasik digunakan untuk menguji normalitas data penelitian, uji multikulinearitas, uji heteroskedastisitas dan uji autokorelasi. Menurut (Sugiono dan Susanto, 2015), uji normalitas bertujuan untuk menguji data penelitian baik variabel dependen maupun variabel independen terdistribusi normal atau tidak dengan menggunakan kolmogrov-smirnow pada taraf signifikan 0,05. Dan uji multikolinieritas digunakan untuk melihat adanya hubungan linier sempurna diantara variabel independennya dengan melihat nilai VIF (Variance Inflasion Factor). Dan uji heteroskedastisitas digunakan untuk mengetahui ada atau tidaknya penyimpangan asumsi klasik melalui penyebaran titik yang tidak membentuk pola.

\section{Pengujian Hipotesis}

Uji hipotesis digunakan untuk mengukur besarnya pengaruh variabel independen terhadap variabel dependen. Untuk mengukur seberapa jauh kemampuan model dalam menerangkan variasi dependen digunakan uji koefisien determinasi $\left(\mathrm{R}^{2}\right)$, menurut (Setiawan dan Kusrini, 2010), nilai yang mendekati satu berarti variabel-variabel independen memberikan hampir semua informasi yang dibutuhkan untuk memprediksi variasi variabel dependen. Untuk mengetahui apakah ada model regresi variabel independen secara parsial berpengaruh signifikan terhadap variabel dependen, maka digunakanlah uji $t$, menurut (Siregar, 2014), kaidah pengujian untuk menguji secara parsial yaitu jika $\mathrm{T}_{\text {hitung }} \leq \mathrm{T}_{\text {tabel }}$ maka $\mathrm{H}_{\mathrm{o}}$ diterima dan $\mathrm{H}_{\mathrm{a}}$ ditolak, dan jika $\mathrm{T}_{\text {hitung }} \geq \mathrm{T}_{\text {tabel }}$ maka $\mathrm{H}_{\mathrm{o}}$ ditolak dan $\mathrm{H}_{\mathrm{a}}$ diterima. Dan untuk mengetahui pengaruh semua variabel independen terhadap variabel dependen maka digunakanlah uji $\mathrm{F}$, uji ini dilakukan dengan syarat bila $\mathrm{F}_{\text {hitung }}<\mathrm{F}_{\text {tabel }}$ maka $\mathrm{H}_{\mathrm{o}}$ diterima dan $\mathrm{H}_{\mathrm{a}}$ ditolak, bila $\mathrm{F}_{\text {hitung }}>\mathrm{F}_{\text {tabel }}$ maka $\mathrm{H}_{\mathrm{o}}$ ditolak dan $\mathrm{H}_{\mathrm{a}}$ diterima.

\section{HASIL DAN PEMBAHASAN}

Didalam penelitian ini dikumpulkan data primer untuk mengetahui sejauh mana pengaruh keselamatan $\left(\mathrm{X}_{1}\right)$ dan kesehatan $\left(\mathrm{X}_{2}\right)$ terhadap kinerja karyawan melalui penyebaran angket pada 63 responden yang menjadi sampel penelitian ini. Untuk menjelaskan identitas ini maka peneliti membuat analisis responden data berdasarkan umur dan pendidikan terakhir karyawan. 


\section{PENGARUH KESELAMATAN DAN KESEHATAN KERJA TERHADAP KINERJA KARYAWAN PADA PABRIK KARET \\ PT. KIRANA SAPTA DI PANOMPUAN}

Sebelum melakukan analisis data, terlebih dahulu uji validitas dan reliabilitas. Setelah data valid dan reliabel selanjutnya menentukan uji normalitas dari data penelitian, adapun hasil uji normalitas penelitian ini adalah :

Tabel 1

Hasil Uji Normalitas

\begin{tabular}{|ll|r|}
\hline & & $\begin{array}{c}\text { Unstandard } \\
\text { ized } \\
\text { Residual }\end{array}$ \\
\hline $\mathrm{N}$ & Mean & 63 \\
Normal & Std. & .0000000 \\
Parameters & \\
& Deviation & 3.23813196 \\
Most Extreme & Absolute & .098 \\
Differences & Positive & .051 \\
& Negative & -.098 \\
Test Statistic & & .098 \\
Asymp. Sig. (2-tailed) & & $.200^{\mathrm{c}, \mathrm{d}}$ \\
\hline
\end{tabular}

Berdasarkan hasil tabel di atas, dapat disimpulkan bahwa data dalam penelitian ini berdistribusi normal. Nilai signifikasi yang diperoleh sebesar 0,200 > 0,1 maka $\mathrm{H}_{\mathrm{o}}$ maka diterima.

\section{Gambar 1 Metode grafik uji normalitas}

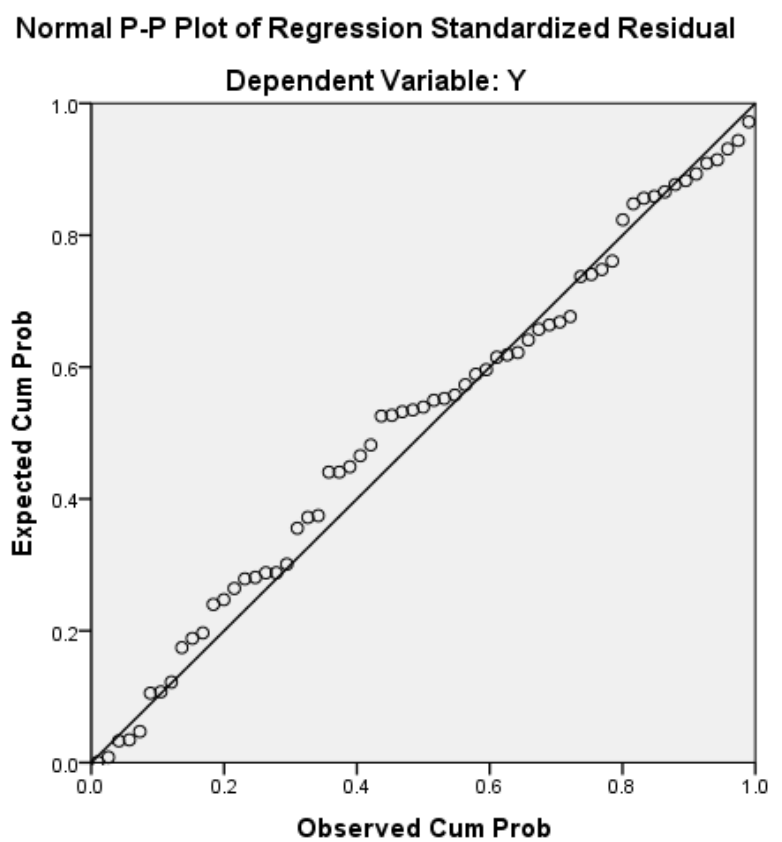


Dari gambar tersebut dapat disimpulkan bahwa titik-titik menyebar disekitar garis diagonal maka data tersebut dapat dikatakan normal.

Dari hasil uji di atas, dapat kita lihat nilai dari Asymp. Sig. (2-tailed) sebesar 0,200 yang nilainya diatas dari 0,05 , apabila hasil perhitungan kolmogrov-smirnow diatas dari 0,05 maka data terdistribusi normal. Sehingga data dalam penelitian ini terdistribusi normal. Jika data sudah normal maka berikutnya adalah menguji multikolinieritas, adapun hasil ujinya adalah :

\section{Hasil Uji Multikolinearitas}

\begin{tabular}{|c|c|c|c|}
\hline \multirow[b]{2}{*}{ Model } & & \multicolumn{2}{|c|}{$\begin{array}{c}\text { Collinearity } \\
\text { Statistics }\end{array}$} \\
\hline & & $\begin{array}{c}\text { Toleranc } \\
\mathrm{e}\end{array}$ & VIF \\
\hline 1 & $\begin{array}{l}\text { (Constant } \\
\text { ) }_{1}\end{array}$ & כ60 & 2816 \\
\hline & $\mathrm{X} 2$ & .262 & 3.816 \\
\hline
\end{tabular}

Berdasarkan nilai tabel di atas dapat diketahui nilai VIF dari tabel variabel keselamatan $\left(\mathrm{X}_{1}\right)=3,816<10$, nilai VIF variabel kesehatan $\left(\mathrm{X}_{2}\right)=3,816<10$. Berdasarkan nilai VIF disimpulkan bahwa variabel keselamatan $\left(\mathrm{X}_{1}\right)$ dan kesehatan $\left(\mathrm{X}_{2}\right)$ dari multikolinearitas. Sementara itu nilai tolerance untuk variabel keselamatan $\left(\mathrm{X}_{1}\right)=0,262>01$, dan variabel kesehatan $\left(\mathrm{X}_{2}\right)=0,262>0,1$. Berdasarkan penilaian dari tabel di atas maka dapat disimpulkan tidak terjadi multikolinieritas antara variabel bebas.:

\section{Gambar 2}

\section{Hasil Uji Heteroskedastisitas}

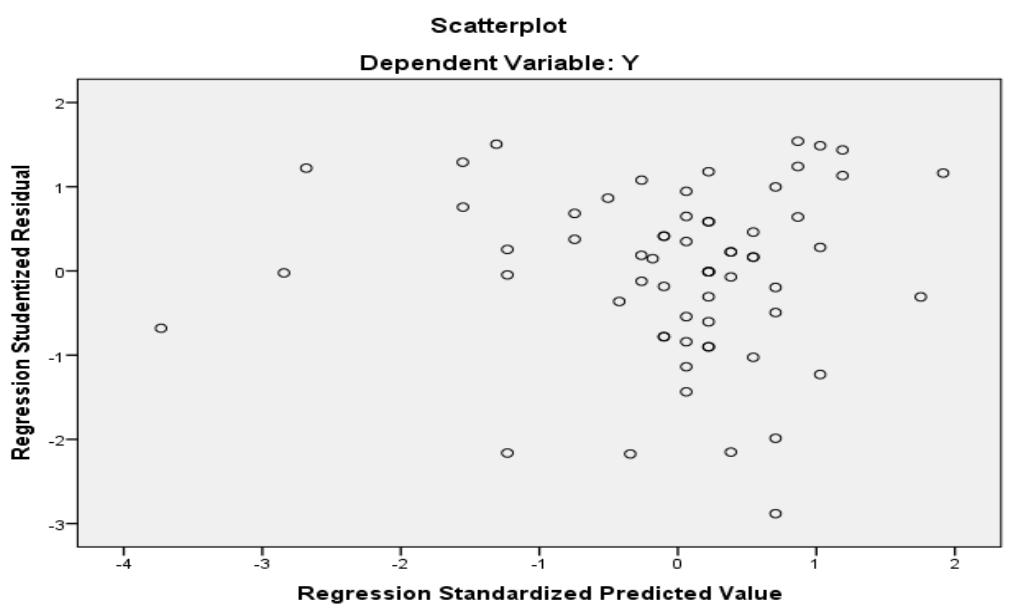




\section{PENGARUH KESELAMATAN DAN KESEHATAN KERJA TERHADAP KINERJA KARYAWAN PADA PABRIK KARET PT. KIRANA SAPTA DI PANOMPUAN}

Berdasarkan gambar di atas dapat dilihat bahwa tidak ada pola yang jelas, seperti titik-titik menyebar di atas dan di bawah angka o pada sumbu Y. Jadi dapat disimpulkan bahwa tidak terjadi heterokedastisitas.

Untuk mengetahui pengaruh keselamatan dan kesehatan kerja terhadap kinerja karyawan pada pabrik karet PT. Kirana Ssapta di Panompuan digunakan program SPSS (Statistical Product Solution Service) versi 23, dengan persamaan regresi yang terbentuk :

Tabel 3

Analisis Regresi Linier Berganda

\begin{tabular}{|c|c|c|c|c|c|}
\hline \multirow[b]{2}{*}{ Model } & \multicolumn{2}{|c|}{$\begin{array}{c}\text { Unstandardized } \\
\text { Coefficients }\end{array}$} & \multirow{2}{*}{\begin{tabular}{|c|}
$\begin{array}{c}\text { Standardiz } \\
\text { ed } \\
\text { Coefficient } \\
\text { S }\end{array}$ \\
Beta \\
\end{tabular}} & \multirow[b]{2}{*}{$\mathrm{t}$} & \multirow[b]{2}{*}{ Sig. } \\
\hline & B & Std. Error & & & \\
\hline $\begin{array}{l}\text { (Consta } \\
\text { nt) }\end{array}$ & 43.102 & 5.847 & & $7 \cdot 371$ & .000 \\
\hline $\mathrm{X} 1$ & .583 & .223 & .596 & 2.614 & .011 \\
\hline $\mathrm{X} 2$ & .825 & .232 & .812 & 3.563 & .001 \\
\hline
\end{tabular}

Kinerja Karyawan $=43,102+0,583$ keselamatan kerja $+0,825$ kesehatan kerja

Untuk mengetahui seberapa besar pengaruh variabel independen terhadap variabel dependennya, dapat dilihat pada tabel berikut :

Tabel 4

Hasil Uji Determinasi $\mathbf{R}^{2}$

\begin{tabular}{|l|c|r|r|c|}
\hline Model & $\mathrm{R}$ & $\begin{array}{c}\mathrm{R} \\
\text { Square }\end{array}$ & $\begin{array}{c}\text { Adjusted R } \\
\text { Square }\end{array}$ & $\begin{array}{c}\text { Std. Error of the } \\
\text { Estimate }\end{array}$ \\
\hline 1 & $.428^{\mathrm{a}}$ & .183 & .156 & 3.292 \\
\hline
\end{tabular}

Berdasarkan tabel tersebut, diketahui bahwa nilai $\mathrm{R}^{2}$ (Adjusted $R$ Square)= 0,156 mendekati 1. Hal ini menunjukkan bahwa 15,6\% variabel keselamatan dan kesehatan memengaruhi kinerja karyawan. Sedangkan 84,4\% (100 - 15,6) dipengaruhi oleh faktor lain yang tidak disebutkan dalam penelitian ini. 


\section{Pembuktian Hipotesis}

Uji hipotesis dalam penelitian ini terdiri dari uji T dan uji $\mathrm{F}$.

Tabel 5

Hasil uji t

\begin{tabular}{|c|c|c|c|c|c|}
\hline \multirow[b]{2}{*}{ Model } & \multicolumn{2}{|c|}{$\begin{array}{c}\text { Unstandardized } \\
\text { Coefficients }\end{array}$} & \multirow{2}{*}{$\begin{array}{c}\text { Standardi } \\
\text { zed } \\
\text { Coefficien } \\
\text { ts } \\
\\
\text { Beta }\end{array}$} & \multirow[b]{2}{*}{$\mathrm{T}$} & \multirow[b]{2}{*}{ Sig. } \\
\hline & B & $\begin{array}{l}\text { Std. } \\
\text { Error }\end{array}$ & & & \\
\hline $\begin{array}{l}\text { (Consta } \\
\mathrm{nt})\end{array}$ & 43.102 & 5.847 & & $7 \cdot 371$ & .000 \\
\hline $\mathrm{X} 1$ & .583 & .223 & .596 & 2.614 & .011 \\
\hline $\mathrm{X} 2$ & .825 & .232 & .812 & 3.563 & .001 \\
\hline
\end{tabular}

Berdasarkan tabel tersebut dapat dilihat bahwa nilai thitung keselamatan $\left(\mathrm{X}_{1}\right)=$ 2,614> tabel 1,672 maka Ho ditolak Ha diterima, sehingga kesimpulannya terdapat pengaruh yang signifikasi antara keselamatan terhadap kinerja karyawan. Nilai thitung kesehatan $\left(\mathrm{X}_{2}\right)=3,563>$ tabel maka $\mathrm{H}_{\mathrm{o}}$ ditolak dan $\mathrm{H}_{\mathrm{a}}$ diterima, sehingga kesimpulannya terdapat pengaruh yang signifikasi antara kualitas terhadap kinerja karyawan.

Uji simultan atau uji $\mathrm{F}$ bertujuan untuk mengetahui pengaruh variabel independen secara bersama-sama berpengaruhkah atau tidak terhadap variabel dependennya dengan membandingkan antara nilai $\mathrm{F}$ hitung dan $\mathrm{F}$ tabel.

Tabel 6 Hasil Uji F

\begin{tabular}{|l|r|r|r|r|r|}
\hline Model & \multicolumn{1}{|c|}{$\begin{array}{c}\text { Sum of } \\
\text { Squares }\end{array}$} & Df & $\begin{array}{c}\text { Mean } \\
\text { Square }\end{array}$ & F & Sig. \\
\hline $1 \quad \begin{array}{l}\text { Regressi } \\
\text { on }\end{array}$ & 145.836 & 2 & 72.918 & 6.730 & $.002^{\mathrm{b}}$ \\
$\quad$ Residual & 650.101 & 60 & 10.835 & & \\
$\quad$ Total & 795.937 & 62 & & & \\
\hline
\end{tabular}




\section{PENGARUH KESELAMATAN DAN KESEHATAN KERJA TERHADAP KINERJA KARYAWAN PADA PABRIK KARET PT. KIRANA SAPTA DI PANOMPUAN}

Berdasarkan tabel tersebut nilai $F_{\text {hitung }}$ yang diperoleh adalah $6,730>\mathrm{F}_{\text {tabel }}=$ 3,15, maka variabel bebas yaitu keselamatan dan kesehatan secara bersama-sama (simultan) berpengaruh terhadap variabel terikat yaitu kinerja karyawan.

\section{KESIMPULAN}

Berdasarkan hasil penelitian dalam skripsi ini, maka penulis menghindari beberapa kesimpulan: pertama, Berdasarkan uji koefisien determinasi $\left(\mathrm{R}^{2}\right)$ diperolah hasil Hasil nilai $\mathrm{R}^{2}$ (Adjusted $R$ Square) = o, 156 mendekati 1. Hal ini menunjukkan bahwa 0,156 atau 15, 6\% variabel keselamatan dan kesehatan terhadap kinerja karyawan. Sedangkan $84,4 \%(100-15,6)$ dipengaruhi oleh faktor lain yang tidak disebutkan dalam penelitian ini. Kedua Hasil uji t dengan taraf signifikasi $10 \%$ menunjukkan bahwa variabel keselamatan nilai thitung2,614> ttabel 1, 670 maka $\mathrm{H}_{\mathrm{o}}$ ditolak dan $\mathrm{H}_{a}$ diterima dan variabel kesehatannilai thitung3,563 > tabel 1, 670, sehingga kesimpulannya secara parsial terdapat pengaruh yang signifikan anatara variabel bebas dan ( keselamatan $\mathrm{X}_{1}$ ), ( kesehatan $\mathrm{X}_{2}$ ) terhadap kinerja karyawan. Ketiga, Hasil uji $\mathrm{F}$ menunjukkan bahwa Fhitung yang diperoleh adalah 6,730 >

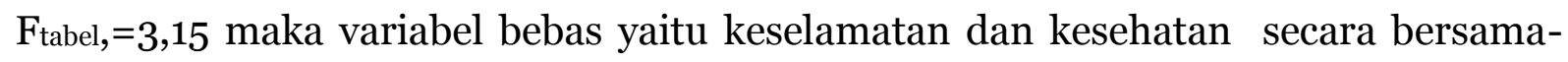
sama (simultan) berpengaruh terhadap variabel terikat yaitu kinerja karyawan.

\section{DAFTAR PUSTAKA}

A.A Anwar Prabu Mangkunegara, Evaluasi Kinerjs SDM (Bandung: PT Refika Aditama, 2012).

Akdon, Strategic Manajemen (Bandung :Alfabeta, 2011).

Departemen Agama RI, Al - Qur'an dan Terjemahannya (Bandung: CV Penerbit Diponegoro, 2010).

Lalu Husni, Pengantar Hukum Ketenagakerjaan (Jakarta: Raja Frafindo, 2015)

Marwansyah, Manajemen Sumber Daya Manusi, (Bandung: Alfabeta, 2014). 
Noor, Juliansyah. 2015. Metodologi Penelitian, Jakarta : Penerbit Kencana.

Rika Hampuh Hadiguna, Manajemen Pabrik, Pendekatan Sistem Untuk Efesiensi dan Efektifitas (Jakarta: BumiAksara, 2009).

Setiawan dan Kusrini, Endah, Dwi. 2010. Ekonometrika, Yogyakarta : Andi.

Siregar, Syofian. 2014. Statistik Parametrik untuk Penelitian Kuantitatif, Jakarta : Bumi Aksara.

Sugiono dan Susanto, Agus. 2015. Cara Mudah Belajar SPSS dan Lisrel Teori Dan Aplikasi Untuk Analisis Data Penelitian, Bandung : Alfabeta.

Surya Darma, Manajemen Kerja, (Yogyakarta :PustakaPelajar, 2005).

Zaeni Asyhadie, Hukum Ketenagakerjaan Bidang Hubungan Kerja (Jakarta: PT Raja GrafindoPersada, 2008). 